\title{
Poly(ADP-ribose) polymerase 1 binds to Pax8 and inhibits its transcriptional activity
}

\section{Tina Di Palma, Tiziana de Cristofaro, Chiara D’Ambrosio', Dolores Del Prete, Andrea Scaloni ${ }^{1}$ and Mariastella Zannini}

\author{
Department di Biologia e Patologia Cellulare e Molecolare, Istituto di Endocrinologia e Oncologia Sperimentale 'G. Salvatore’-CNR, Universita' di Napoli Federico II, Via S. Pansini 5, \\ 80131 Napoli, Italy \\ ${ }^{1}$ Proteomics and Mass Spectrometry Laboratory, ISPAAM-CNR, 80147, Napoli, Italy
}

(Correspondence should be addressed to M Zannini; Email: s.zannini@ieos.cnr.it)

\begin{abstract}
Pax8 is a transcription factor that plays an important role in the regulation of genes that are exclusively expressed in differentiated thyroid cells. In the thyroid cell environment, evidence exists that Pax 8 is part of a multiprotein complex in which its transcriptional activity may be modulated by specific co-factors. In an attempt to identify proteins that interact with Pax8, we performed pull-down experiments challenging the GST-Pax8 fusion protein with protein extracts prepared from the thyroid differentiated cell line PC Cl3. By this approach, we isolated a 113-kDa protein that is able to associate with Pax8, which was further identified by mass fingerprint experiments as poly(ADP-ribose) polymerase 1 (PARP1). To further confirm this interaction, we also showed that PARP1 can be co-immunoprecipitated with Pax8 in vivo from a thyroid cell extract. Gel shifts experiments demonstrated that PARP1 binding to Pax 8 significantly inhibits Pax 8 binding to DNA. Accordingly, we provide evidence that the functional outcome of such an interaction is a significant downregulation of Pax8 transcriptional activity. In the context of thyroid-specific gene transcription, our results suggest that PARP1 behaves as an important negative co-factor involved in the regulation of Pax8-dependent gene expression.
\end{abstract}

Journal of Molecular Endocrinology (2008) 41, 379-388

\section{Introduction}

Transcription factors act in a combinatorial fashion with an intricate array of co-regulators and with the general transcriptional machinery to allow tissuespecific gene expression and gene activation pathways. The interplay between sequence-specific transcription factors and co-regulator complexes determine the access to DNA either through acetylating reactions mediated by histone acetyltransferases (Xu et al. 1999) or through nucleosome-remodeling complexes (Muchardt \& Yaniv 1999). Precise spatial and temporal switches in patterns of gene activation/repression are critical for the regulation of cell growth, differentiation and proper organ development. The differentiation program of thyroid follicular cells (TFCs) is completed only when the gland reaches its final location in front of the trachea and it depends on the crosstalk between transcription factors and transcriptional co-regulators with the basal transcriptional machinery of the cells. Differentiated TFCs are responsible for thyroid hormone synthesis and are characterized by the expression of a specific set of genes such as thyroglobulin ( $\mathrm{Tg}$ ) and thyroperoxidase, which are exclusively expressed in this cell type (Damante \& Di Lauro 1994, Damante et al. 2001) and by the expression of genes expressed only in few tissues other than the thyroid, such as the thyrotropinstimulating hormone receptor and the sodium/iodide symporter.

Pax8 is one of the transcription factors involved in thyroid-specific gene expression (Damante \& Di Lauro 1994, De Felice \& Di Lauro 2004). It is a member of the Pax family of genes that are characterized by the presence of a 128-amino acid DNA binding domain, the paired domain (PD; Plachov et al. 1990). These genes encode for DNA-binding proteins that are involved in the regulation of the development of a variety of tissues in different species. In particular, Pax8 has been shown to be required for both the morphogenesis of the thyroid gland (Mansouri et al. 1998) and for the maintenance of the thyroid-differentiated phenotype (Pasca di Magliano et al. 2000). Interestingly, in Pax8 knockout mice the thyroid gland is barely visible and lacks the follicular cells (Mansouri et al. 1998). Recently, we have demonstrated that Pax8 interacts biochemically and functionally with TIF1/NKX2.1 (NK2 homeobox 1), another transcription factor involved together with Pax8 in the regulation of thyroid-specific genes (Di Palma et al. 2003).

Given the critical role played by Pax8 in thyrocyte differentiation, we focused our attention on the molecular mechanisms by which Pax 8 modulates thyroid gene expression. Our hypothesis was that Pax8,

DOI: 10.1677/JME-08-0056 Online version via http://www.endocrinology-journals.org 
similarly to other members of the Pax gene family (Fitzsimmons et al. 1996, Wheat et al. 1999), could play a role in the recruitment of other factors and/or co-factors to the gene target promoters by specific protein-protein interactions. In this study, we report on a nuclear protein, namely poly(ADP-ribose) polymerase 1 (PARP1), which was isolated during GSTpull down experiments with thyroid cell lysates using a bait consisting of Pax8 fused to GST. Further experiments confirmed that PARP1 directly interacts with Pax8 in vitro and in vivo, although it does not poly(ADPribosyl)ate it. Transactivation assays finally demonstrated that PARP1 behaves as a Pax8 repressor.

PARP1 is a nuclear enzyme activated by DNA strand breakage that catalyzes the transfer of ADP-ribose units from $\mathrm{NAD}^{+}$to numerous nuclear proteins (de Murcia \& Menissier de Murcia 1994, D'Amours et al. 1999). It participates in several cellular catalytic activities, including anti-recombination and genomic stability (Ding \& Smulson 1994), DNA replication (SimbulanRosenthal et al. 1998), apoptosis regulation and DNA repair (Jeggo 1998, Pieper et al. 1999). Recent studies have also underlined its role in the regulation of gene transcription (D'Amours et al. 1999, Chiarugi 2002, Kraus \& Lis 2003) and as a partner of several transcription factors and (co)-factors, including NF-kB (Hassa et al. 2003, Nakajima et al. 2004), AP-2 (Kannan et al. 1999), B-MYB (Cervellera \& Sala 2000), E2F-1 (Simbulan-Rosenthal et al. 2003), RAR/RXR (Miyamoto et al. 1999, Pavri et al. 2005) and p53 (Kumari et al. 1998). Recently, another member of the PARP family, namely PARP2, and PARP1 were identified as interacting proteins of the transcription factor TIF1/NKX2-1 (Maeda et al. 2006).

Accordingly, the results here reported suggest that the interaction between PARP1 and Pax8 may significantly affect a series of molecular events related to Pax8-dependent gene expression, thus disclosing important scenarios on mechanisms playing a central role in the regulation of thyroid-specific transcription.

\section{Materials and methods}

\section{Reporter constructs and expression plasmids}

The plasmids used have been previously described and are as follows: Tg-CAT (Sinclair et al. 1990), CP5-CAT (Missero et al. 1998), GST-Pax8 (Di Palma et al. 2003), GST-PD (pGEX-Pax8PB; Zannini et al. 1992), pCMV5Pax8 (Zannini et al. 1992), and pPARP31 (Van Gool et al. 1997). The latter was kindly provided by Dr Kannan (MetroHealth Medical Center, Cleveland, OH, USA).

\section{Protein identification by mass spectrometry}

GST and GST-Pax8 proteins were purified from BL21 (DE) LysS bacterial cells as previously described (Zannini et al. 1992, Di Palma et al. 2003). The purified proteins were loaded onto glutathione-Sepharose beads (GE Healthcare, Waukesha, WI, USA) at a concentration of $1 \mu \mathrm{g} / \mu \mathrm{l}$ packed beads for $20 \mathrm{~min}$ at $4{ }^{\circ} \mathrm{C}$.

A total of $5 \times 10^{8} \mathrm{PC} \mathrm{Cl} 3$ cells were lysed; after a preclearing step on of GST-coated beads, the total extract was adsorbed with GST and GST-Pax8 beads. After washing, the bound proteins were resolved by SDSPAGE, and visualized by ammoniacal silver staining according to Shevchenko's protocol (Shevchenko et al. 1996). For identification, protein bands were excised from the gel, triturated, in-gel S-alkylated and digested with trypsin as previously reported (Caratu et al. 2007, Vascotto et al. 2007). Gel particles were extracted with $25 \mathrm{mM} \mathrm{NH}_{4} \mathrm{HCO}_{3}$ /acetonitrile $(1: 1 \mathrm{v} / \mathrm{v})$ by sonication. Samples were desalted using microZipTipC18 pipette tips (Millipore, Bredford, MA, USA) before MALDITOF-MS analysis. Peptide mixtures were loaded on the MALDI target together with a-cyano-4-hydroxycinnamic acid as matrix, using the dried droplet technique. Samples were analyzed with a Voyager-DE PRO spectrometer (Applera, Foster City, CA, USA; Caratu et al. 2007, Vascotto et al. 2007). Mass spectra were acquired in reflectron mode; internal mass calibration was performed with peptides from trypsin autoproteolysis. Data were elaborated using the DataExplorer 5.1 software (Applera, USA). ProFound software (Zhang \& Chait 2000) was used to identify protein bands from an NCBI non-redundant database using peptide mass fingerprint data. Candidates with program Est'd Z scores more than 2 were further evaluated by comparison with $\mathrm{Mr}$ experimental values obtained from SDSPAGE. Eventual occurrence of protein mixtures was ascertained by sequential searches for additional protein components using unmatched peptide masses.

\section{Protein extracts and immunoblotting}

For reporter assays, cells were washed twice with ice-cold PBS and lysed in a buffer containing $10 \mathrm{mM}$ HEPES $\mathrm{pH}$ $7 \cdot 9,400 \mathrm{mM} \mathrm{NaCl}, 0 \cdot 1 \mathrm{mM}$ EGTA $\mathrm{pH} 7 \cdot 8,5 \% \mathrm{v} / \mathrm{v}$ glycerol, $1 \mathrm{mM}$ dithiothreitol (DTT), $1 \mathrm{mM}$ phenylmethylsulfonyl fluoride (PMSF). For GST-pull down assays, PC Cl3 cells were washed twice with PBS and lysed in whole cell extract (WCE) buffer containing $50 \mathrm{mM}$ Tris $\mathrm{pH} 7 \cdot 5,100 \mathrm{mM} \mathrm{NaCl}, 0 \cdot 1 \%$ Triton X100, $10 \% \mathrm{v} / \mathrm{v}$ glycerol, $1 \mathrm{mM}$ DTT, $1 \mathrm{mM}$ PMSF and protease inhibitors (Sigma). For immunoprecipitation experiments, cells were washed twice with PBS and lysed in EBC buffer containing $50 \mathrm{mM}$ Tris $\mathrm{pH} 7 \cdot 5,120 \mathrm{mM}$ $\mathrm{NaCl}, 0.5 \%$ Nonidet P-40, $10 \%$ glycerol, $1 \mathrm{mM}$ DTT, $1 \mathrm{mM}$ PMSF and protease inhibitors (Sigma). 
Protein concentration was determined using the BioRad protein assay (Bio-Rad Laboratories Inc). For western blot analysis, proteins were separated by SDSPAGE and the gels were blotted onto Immobilon $\mathrm{P}$ (Millipore) for $2 \mathrm{~h}$; membranes were blocked in $5 \%$ nonfat dry milk in Tris-bufferd saline for $2 \mathrm{~h}$ or overnight before the addition of antibody for $1 \mathrm{~h}$. The primary antibodies used were anti-PARP1 (46D11; Cell Signaling, Boston, MA, USA), anti-Pax8 (kindly provided by Di Lauro), anti-PAR (96-10-04; Alexis ,San Diego, CA, USA) and anti-FLAG-M2 (Sigma).

\section{Pull down assays and co-immunoprecipitation}

GST-PD and GST-Pax8 proteins were purified from BL21 (DE) LysS bacterial cells as previously described (Zannini et al. 1992, Di Palma et al. 2003).

GST, GST-Pax8 or GST-PD bound to glutathione beads were incubated with total protein extract prepared from $\mathrm{PC} \mathrm{Cl} 3$ cells, or with $25 \mathrm{ng}$ recombinant human PARP1 (ALX-201-063; Alexis). The binding reactions were carried out for $90 \mathrm{~min}$ at $4^{\circ} \mathrm{C}$ on a rotating wheel. After extensive washing with WCE buffer, bound proteins were detected by western blot.

Co-immunoprecipitation experiments were performed by incubating $3 \mathrm{mg}$ total protein extract with $40 \mu \mathrm{l}$ anti-FLAG agarose affinity gel (Sigma), overnight, at $4{ }^{\circ} \mathrm{C}$, on a rotating wheel. Bound proteins were washed several times with EBC buffer, resuspended in SDS-PAGE sample buffer and heated at $95^{\circ} \mathrm{C}$ for $5 \mathrm{~min}$, before loading on the gel. Alternatively, $3 \mathrm{mg}$ total protein extracts were pre-cleared with $100 \mu$ l Protein A-Sepharose (GE Healthcare) and immunoprecipitated with PARP1 polyclonal antibody (46D11, Cell Signaling) overnight at $4^{\circ} \mathrm{C}$ on a rotating wheel in EBC buffer. Hundred microliters protein A-Sepharose were added, and the samples were rocked for $1 \mathrm{~h}$ at $4^{\circ} \mathrm{C}$. After several washes with EBC buffer the bound protein were resuspended in 2X SDS-PAGE sample buffer and heated at $95^{\circ} \mathrm{C}$ for $5 \mathrm{~min}$ before loading on the gel.

\section{Poly(ADP-ribosyl)ation in vitro}

6 His-Pax 8 purified recombinant protein $(50,100$, and $150 \mathrm{ng}$ ) and recombinant human PARP1 (Alexis; $25 \mathrm{ng}$ ) were incubated for $10 \mathrm{~min}$ at $37^{\circ} \mathrm{C}$ in binding buffer (10 mM Tris-HCl, pH 7.5, $1 \mathrm{mM} \mathrm{MgCl}_{2}, 1 \mathrm{mM}$ DTT) plus $10 \mu \mathrm{g} / \mathrm{ml}$ of sonicated DNA. In some reaction mixtures, $10 \mathrm{mM}$ 3-aminobenzamide (3-AB; Sigma) was included. The reactions were started by adding $5 \mu \mathrm{Ci}(0 \cdot 25 \mu \mathrm{M}){ }^{32}$ P-labeled $\mathrm{NAD}^{+}$(GE Healthcare), and incubated at $37^{\circ} \mathrm{C}$ for 10 additional minutes. After terminating the reactions with SDS sample buffer, the proteins were fractionated by SDS-PAGE through a
4-15\% gradient gel. Poly(ADP-ribosyl)ated proteins were visualized by autoradiography.

For pull down experiments with purified proteins, recombinant human PARP1 (Alexis; $25 \mathrm{ng}$ ) was incubated for $10 \mathrm{~min}$ at $37^{\circ} \mathrm{C}$ in a mixture $(20 \mu \mathrm{l})$ containing $10 \mathrm{mM}$ Tris- $\mathrm{HCl}$, pH 7·5, $1 \mathrm{mM} \mathrm{MgCl}_{2}, 1 \mathrm{mM}$ DTT, plus $10 \mu \mathrm{g} / \mathrm{ml}$ of sonicated DNA. In this case, the reaction was started by adding $200 \mu \mathrm{M} \beta \mathrm{NAD}^{+}$(Sigma) and further incubated for another $15 \mathrm{~min}$. The SDS sample buffer was added to stop the reaction that was diluted 10-fold in WCE buffer and then used in the pull down assay.

\section{Electrophoretic mobility shift assay (EMSA)}

Double-stranded oligodeoxynucleotide C (5'-CACTGCCCAGTCAAGTGTTCTTGA- ${ }^{\prime}$ ) derived from the $\mathrm{Tg}$ promoter and containing one Pax8 binding site was labeled with $\gamma-{ }^{32} \mathrm{P}$ ATP (GE Healthcare) and T4 polynucleotide kinase. Commercially available human PARP1, GST-Pax8, and GST-PD purified proteins were incubated for $20 \mathrm{~min}$, at room temperature, in a binding buffer containing $10 \mathrm{mM}$ HEPES (pH 7.9), 10\% v/v glycerol, $0 \cdot 1 \mathrm{mM}$ EDTA, $8 \mathrm{mM} \mathrm{MgCl,} 1 \mathrm{mM}$ DTT, $0 \cdot 15 \mu \mathrm{g} / \mathrm{ml}$ of poly (dI-dC). In some reaction mixtures, $\beta_{\mathrm{NAD}}{ }^{+}$(Sigma), 3-AB (Sigma), or both were included. Thus, ${ }^{32}$ P-labeled oligodeoxynucleotide C $(0.8 \mathrm{ng})$ was added, and the mixtures $(20 \mu \mathrm{l})$ were incubated for additional $20 \mathrm{~min}$. DNA-protein complexes were resolved on a $5 \%$ non-denaturing polyacrylamide gel and visualized by autoradiography.

\section{Cell culture and transient transfection assays}

PC Cl3 cells (Fusco et al. 1987, Berlingieri et al. 1988) were grown in Coon's modified F-12 medium (Euroclone) supplemented with $5 \% \mathrm{v} / \mathrm{v}$ calf serum and a sixhormone mixture $(6 \mathrm{H})$, as described by Ambesi-Impiombato \& Coon (1979).

HeLa cells were grown in Dulbecco's modified Eagle's medium (Euroclone) supplemented with $10 \% \mathrm{v} / \mathrm{v}$ fetal calf serum (Hyclone). For transient transfection experiments, cells were plated at $3 \times 10^{5}$ cells $/ 60-\mathrm{mm}$ tissue culture dish 5-8 h prior to transfection, whereas $\mathrm{PC} \mathrm{Cl} 3$ cells were plated at a density of $5 \times 10^{5}$ cells $/ 60-\mathrm{mm}$ tissue culture dish $18 \mathrm{~h}$ prior to transfection. All transfections were carried out with the FuGENE6 reagent (Roche Diagnostics) according to the manufacturer's directions. The DNA/FuGENE ratio was 1:2 in all the experiments. The plasmid CMV-LUC was used as internal control in the transfection assays. Cells extracts were prepared $48 \mathrm{~h}$ after transfection to determine either the levels of the CAT protein with a CAT ELISA kit (Roche Diagnostics) or the LUC activity by a Luciferase assay, as previously described (de Wet et al. 1987). Transfection experiments were done in duplicate 
and repeated at least three times. CAT activity values on the graph are the means of all experiments $( \pm)$ S.D. Statistical analysis uses $t$-test $(P<0 \cdot 002)$.

\section{Results}

\section{A nuclear protein of $113 \mathrm{kDa}$ binds to the transcription factor Pax8}

To identify proteins that are able to interact with the transcription factor Pax8, we used the GST-Pax8 fusion protein in pull down assays with a total protein extract from $5 \times 10^{8}$ PC Cl3 thyroid cells. The extract was precleared onto GST-loaded beads and then was divided and incubated with GST and GST-Pax8 loaded beads. Bound proteins were eluted, analyzed by SDS-PAGE and visualized by ammoniacal silver staining. Several proteins bound specifically to the bait (Fig. 1). Peptide mass fingerprint analysis identified the protein migrating at $113 \mathrm{kDa}$, which was specifically purified via GST-Pax8, as the PARP1 nuclear protein (SwissProt code P27008; Fig. 1). The experiment was performed twice, verifying in the mass spectra the occurrence of 11 and 10 peptides, corresponding to sequence coverage of 19 and $14 \%$, respectively. Other bands of lower molecular weight were identified as GST-Pax8 degradation products (data not shown).

\section{PARP1 interacts with Pax8 in vitro and in vivo}

To confirm PARP1 as a Pax8-interacting protein, we performed small-scale GST-pull down assays incubating the recombinant GST-Pax8 protein with total protein

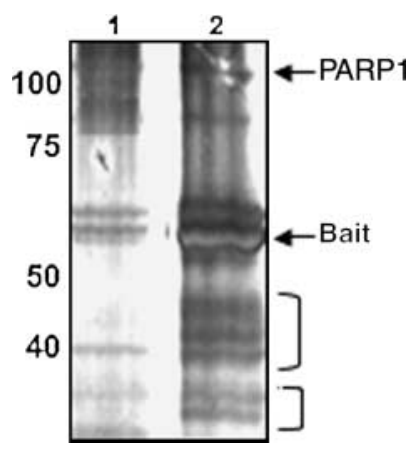

Figure 1 Pax8 interacts with PARP1. To isolate cellular proteins interacting with the GST-Pax8, glutathione-Sepharose beads loaded with GST-Pax8 or GST were incubated with total cell lysate obtained from $\mathrm{PC} \mathrm{Cl} 3$, as described under Materials and Methods. After binding, the eluted proteins were separated on $4-15 \%$ SDS-PAGE and visualized by silver staining. Lane 1, proteins eluted from GST beads. Lane 2, proteins eluted from GST-Pax 8 beads. The arrow indicates the protein band identified by MALDI-TOF peptide mass fingerprint analysis as PARP1. Brackets indicate fragments of the GST-Pax8 bait. Molecular mass markers are indicated on the left. extract from $1 \times 10^{6}$ thyroid cells. The eluted material was loaded onto an SDS-PAGE mini-gel and subjected to western blot with a PARP1 specific polyclonal antibody. As shown in Fig. 2A, only the eluate from GST-Pax8 contained PARP1. To further investigate the hypothesis that Pax 8 and PARP1 are able to interact directly, we performed pull down experiments using the fusion protein GST-Pax8 and purified human PARP1 protein. The beads loaded with GST-Pax8 were indeed able to co-precipitate the purified PARP1 protein, while the beads loaded with the GST protein did not co-precipitate any protein (Fig. 2B). These results demonstrated that the interaction between Pax8 and PARP1, already observed in pull down assays with total protein extracts, is indeed a direct protein-protein interaction.

We then investigated whether the interaction described above could also be observed in vivo. To this end, cell lysates obtained from PC Cl3 (mock transfected) and from a stable clone PC-3xFLAG-Pax8 (Di Palma et al. 2003) were immunoprecipitated with an anti-FLAGagarose affinity gel and then analyzed by western blot with a monoclonal antibody against PARP1. As shown in Fig. 2C, PARP1 was specifically co-immunoprecipitated by anti-FLAG-agarose affinity gel only in the extract prepared from the clone PC-3xFLAG-Pax8, thus demonstrating that Pax8 and PARP1 co-exist in a complex in vivo. Consistent with this result, a PARP1 polyclonal antibody was able to co-immunoprecipitate the 3xFLAG-Pax8 protein (Fig. 2D).

\section{Poly(ADP-ribosyl)ation of purified Pax8 protein}

PARP1 is a nuclear protein that binds to DNA strand breaks and catalyzes ADP-ribosylation of itself and other nuclear protein, using $\mathrm{NAD}^{+}$as a co-factor. In order to examine whether Pax8 is directly modified by PARP1, we incubated purified human PARP1 and 6His-Pax8 purified protein in a reconstituted poly(ADP-ribosyl)ating enzyme system containing ${ }^{32} \mathrm{PNAD}^{+}$to label the modified proteins. The reaction products were then analyzed by SDS-PAGE. As shown in Fig. 3, PARP1 was significantly auto-poly(ADP-ribosyl)ated, as indicated by the radioactive smear visible at a molecular weight higher than $113 \mathrm{kDa}$. The addition of an inhibitor of poly(ADP-ribosyl)ation, namely 3-aminobenzamide, abolished the automodification reaction of PARP1 (Fig. 3, lane 3), as already described. The presence of increasing amount of Pax 8 did not exert a positive effect on the catalytic activity of PARP1 (Fig. 3, lanes 4-6). No poly(ADP-ribosyl)ation signals were instead detected at Pax8 molecular weight. Re-probing of the filter with antibodies against PARP1 and Pax8 confirmed the presence of the proteins in all the reactions and allowed us to conclude that while PARP1 is modified, Pax 8 remains unmodified by poly(ADPribosyl)ation (Fig. 3). 
A

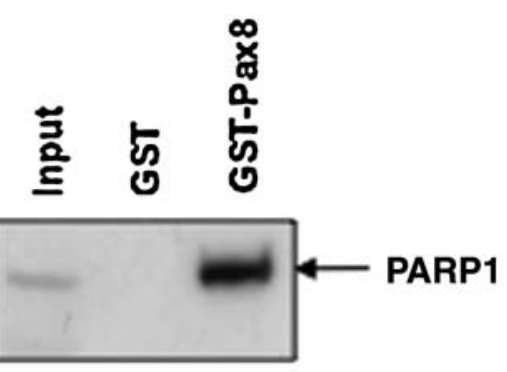

C

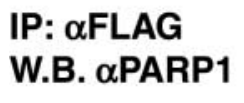

Input

W.B. $\alpha$ FLAG

Input

W.B. $\alpha$ PARP1

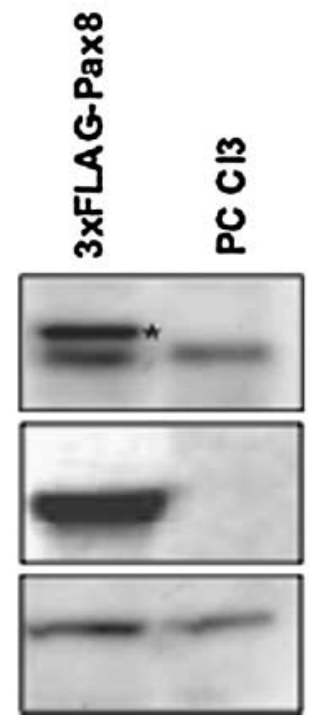

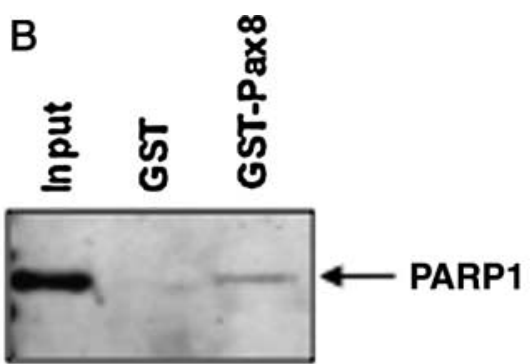

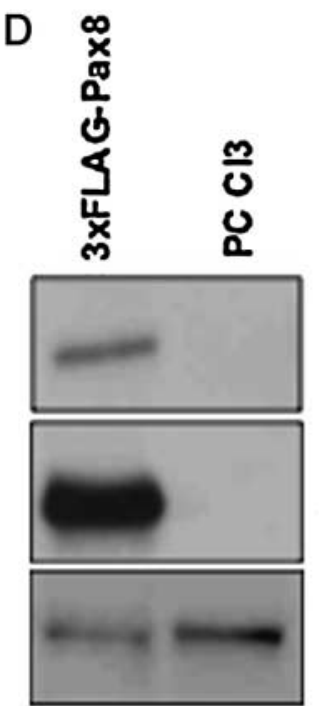

IP: $\alpha$ PARP1

W.B. $\alpha$ FLAG

Input

W.B. $\alpha$ FLAG

Input

W.B. $\alpha$ PARP1

Figure 2 Pax8 and PARP1 interact in vitro and in vivo. GST-pull down assays were performed with GSTPax8 immobilized on glutathione-Sepharose beads. (A) protein extract prepared from $\mathrm{PC} \mathrm{Cl3}$ cells was incubated with GST-Pax8 and with GST alone as control; (B) purified human PARP1 was incubated with GST-Pax8 and with GST alone as control. After the binding reaction, the eluted proteins were loaded onto $10 \%$ SDS-PAGE, and analyzed by western blot using a PARP1-specific polyclonal antibody. The co-immunoprecipitation experiments were performed as follows: (C) three milligrams PC $\mathrm{Cl} 3$ and PC-3xFLAG-Pax8 total protein extract were incubated with anti-FLAG-agarose affinity gel. The asterisk indicates the band corresponding to the PARP1 protein; (D) three milligrams PC Cl3 and PC-3xFLAGPax8 total protein extract were incubated with the anti-PARP1 antibody and Protein A Sepharose. The bound protein (IP) and total lysate cells (Input) were separated on 10\% SDS-PAGE and analyzed by western blot using a PARP1-specific polyclonal antibody and an anti-FLAG monoclonal antibody.

\section{PARP1 binds the PD of Pax8 and inhibits its DNA- binding activity}

To investigate the effect of the interaction with PARP1 on the Pax8 DNA-binding activity, EMSA assays were performed with bacterially expressed and purified proteins. The results reported in Fig. 4A show that the addition of increasing amounts of PARP1 to Pax8 caused a strong reduction of Pax8 binding to the double-stranded oligonucleotide containing its consensus sequence. At the same time, no retarded bands were observed in the reaction with PARP1 protein alone, thus suggesting that PARP1 cannot bind to the same oligonucleotide. We considered the possibility of explaining the results reported above on the basis of a putative interaction of PARP1 with Pax8 DNA-binding domain, the PD. To test this hypothesis, we performed GST-pull down assays using the GST-PD (GST-PD) fusion protein and purified PARP1 protein. Results of the binding reactions demonstrated that GST-PD was indeed able to co-precipitate PARP1 protein with the same efficiency as GST-Pax8 (Fig. 4B). In order to elucidate whether poly(ADP-ribosyl)ated PARP1 retained an equal ability to interact with Pax8, PARP1 extensively modified in vitro was incubated with matrixbound GST or GST-Pax8. Results of the binding reactions showed that poly(ADP-ribosyl)ated PARP1 interacts with Pax8 to the same extent as unmodified PARP1 (Figs 2A and 4C). The same result was obtained when GST-PD was used in place of GST-Pax8 (data not shown). Altogether, these data demonstrated that the 


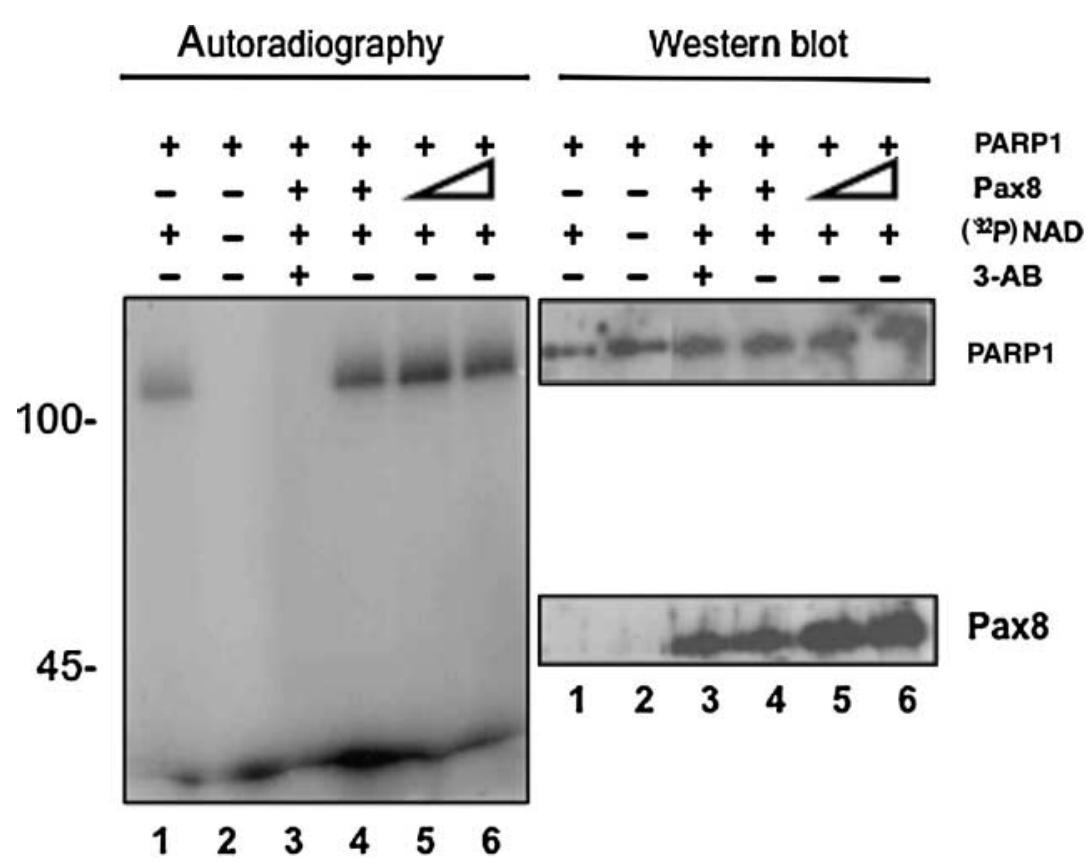

Figure 3 Susceptibility of Pax8 to covalent poly(ADP-ribosyl)ation in vitro. Twenty five nanograms of PARP1 were incubated in the absence (lanes 1 and 2) or presence of $50 \mathrm{ng}$ (lanes 3 and 4) $100 \mathrm{ng}$ (lane 5) and $150 \mathrm{ng}$ (lane 6) of $6 \mathrm{His}-\mathrm{Pax} 8$, of $0.25 \mu \mathrm{M}^{32} \mathrm{P}$-labeled $\mathrm{NAD}^{+}, 10 \mu \mathrm{g} / \mathrm{ml}$ of sonicated DNA, $10 \mathrm{mM}$ of 3-aminobenzamide (lane 3), at room temperature. Reactions were started by adding of ${ }^{32}$ PNAD and stopped by the addition of Laemmli buffer. Proteins were fractionated by SDS-PAGE through 4-15\% gradient gel and subjected to western blot. The poly(ADP-ribosyl)ated proteins were visualized by autoradiography. The same filter was probed with anti- PARP1 and anti-Pax8 antibodies. The molecular weight markers are shown on the left.

interaction between Pax8 and PARP1 occurs via Pax8 PD and it is not affected by PARP1 automodification.

To further confirm the results reported above, we carried out EMSA assays with bacterially produced and purified GST-PD and modified or unmodified PARP1 protein. As shown in Fig. 4D, the addition of PARP1 inhibited GST-PD binding to DNA both in the absence or presence of $\mathrm{BNAD}^{+}$(lanes 3 and 4 ). Along the same line, the inhibition of the auto-poly(ADP-ribosyl)ation reaction of PARP1 with 3-AB led to the same inhibition of Pax8-PD binding to DNA (lane 5).

In conclusion, these data consistently suggested that, independent of the poly(ADP-ribosyl)ation reaction, the PARP1 interaction with Pax8 negatively influences the DNA-binding activity of the transcription factor.

\section{PARP1 behaves as a transcriptional repressor for Pax8}

Since we demonstrated that PARP1 binds to Pax8 DNAbinding domain, we hypothesized that the interaction between the two proteins could affect Pax8 transactivating properties. To elucidate whether this physical interaction between Pax 8 and PARP1 could affect Pax 8 transcriptional activity, we performed transactivation assays in HeLa cells co-transfecting the reporter construct CP5-CAT, an artificial promoter responsive only to Pax8, together with the expression vectors encoding for Pax 8 and PARP1, separately or in combination. As expected, the transfection of Pax8 alone led to a significant activation of the CP5-CAT promoter, while the transfection of PARP1 alone decreased by the basal activity of the promoter only a little, due to its suppressive activity on RNA polymerase (Oei et al. 1998; Fig. 5A). Interestingly, the co-expression of Pax8 and PARP1 led to an inhibition of Pax8dependent transcription (Fig. 5A). The same effect was observed in the thyroid differentiated cell line PC Cl3. Also in this case, over-expression of PARP1 produced a significant reduction of the transcriptional activity of endogenously expressed Pax8 on the transfected CP5CAT promoter (Fig. 5B). To further investigate whether PARP1 could inhibit Pax8 transcriptional activity not only on the synthetic promoter CP5-CAT, but also in a more physiological context represented by the $\mathrm{Tg}$ promoter, we repeated the same transactivation assays described before, this time using the reporter Tg-CAT.

Therefore, we co-transfected the expression vector encoding for PARP1 in PC Cl3 cells together with the 
reporter construct Tg-CAT. Also in these experiments, we observed that PARP1 decreased the transcriptional activity of endogenous Pax 8 on the Tg-CAT promoter in an analogous manner to that observed on the CP5-CAT promoter (Fig. 5C).

A

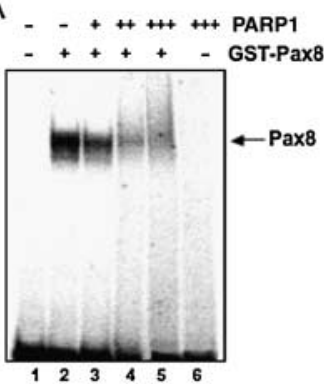

B

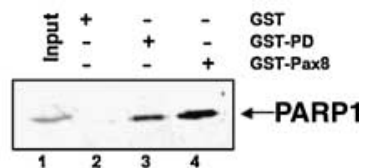

C

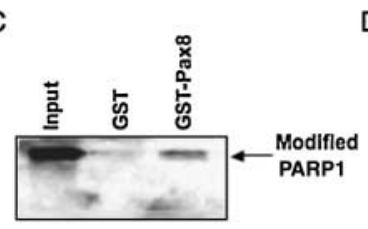

D

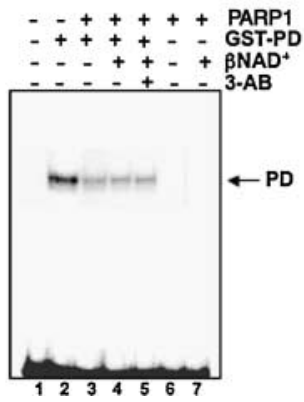

Figure 4 Independently of its automodification PARP1 interacts with Pax8-PD and inhibits its specific DNA binding. (A) EMSA was performed as described under experimental procedures. Increasing amounts of PARP1 (range of $0(-), 0.2(+), 0.5(++), 1$ $(+++) \mu \mathrm{g})$ were incubated with GST-Pax8 $(0(-), 0.05(+) \mu \mathrm{g})$ for $20 \mathrm{~min}$, at room temperature. After electrophoresis on native $5 \%$ polyacrylamide gels, Pax8-oligodeoxynucleotide complexes were visualized by autoradiography. Lane 1, DNA probe control; lane 2, GST-Pax8 control; lanes 3-5, effect of PARP1 on Pax8 mobility shift; lane 6, PARP1 control. (B) Bacterially produced GSTPD, GST-Pax8 or GST alone was mixed with glutathioneSepharose beads and incubated with an equivalent amount of purified PARP1. The eluted proteins were loaded onto a $10 \%$ SDSPAGE, and analyzed by western blot using a PARP1-specific monoclonal antibody, Lane 1, purified PARP1. Lane 2, PARP1 protein precipitated with GST for control. Lane 3, PARP1 protein precipitated with GST-PD. Lane 4, PARP1 protein precipitated with GST-Pax8. (C) In vitro modified PARP1 as described under experimental procedures was incubated with GST-Pax8 or GST as control. Both GST and GST-Pax8 beads were washed several times before being loaded onto a $4 \%$ to $15 \%$ gradient gel, and analyzed by western blot with anti-PAR, a polyclonal antibody to Poly(ADP-ribose). (D) EMSA was performed as described above. PARP1 $(0(-), 0.5(+) \mu \mathrm{g})$ and GST-PD $(0(-), 0.015(+) \mu \mathrm{g})$ were co-incubated in the absence $(-)$ or presence $(+)$ of $200 \mu \mathrm{M}$ $\mathrm{BNAD}^{+}$. Lane 5, shows the effect of $10 \mathrm{mM}$ 3-aminobenzamide. After electrophoresis on native $5 \%$ polyacrylamide gels, PD-oligodeoxynucleotide complexes were visualized by autoradiography. Lane 1, DNA probe control; lane 2, GST-PD control; lanes 3-5, effect of native or modified PARP1 on PD mobility shift; lane 6, PARP1 control; lane 7, modified PARP1 control.

\section{Discussion}

It is well known that the activity of transcription factors is regulated by the physical interaction with coactivators and co-repressor molecules. This crosstalk plays a pivotal role in the determination and maintenance of the cellular differentiated phenotype. Among the transcription factors involved in thyroid-specific gene expression, Pax8, a member of the Pax gene family, plays a critical role in the expression of all the thyroid-specific genes that are considered markers of the differentiated phenotype (Pasca di Magliano et al. 2000). The analysis of knockout mice confirmed that Pax8 has a key role in the development and differentiation of the thyroid gland. In fact, Pax8 knockout mice have a very small thyroid gland, which is deprived of follicular cells (Mansouri et al. 1998). Recently, it has been demonstrated that Pax 8 cooperates with the transcription factor NKX2-1 (Espinoza et al. 2001, Miccadei et al. 2002), and our laboratory specifically demonstrated that Pax8 and NKX2-1 form a functional heterocomplex responsible for the synergistic transcriptional activation of the $\mathrm{Tg}$ promoter in differentiated thyroid cells (Di Palma et al. 2003). The relevance of this interaction has been further confirmed by the analysis of the in vivo mouse model bearing a partial deficiency of Ttf1 and Pax8 genes. The double-heterozygous null mice show thyroid dysgenesis, a phenotype that is completely absent in either of the single heterozygous mice (Amendola et al. 2005). To identify proteins interacting with Pax8 that could modulate its transcriptional activity, a protein lysate obtained from the thyroid differentiated cell line PC Cl3 was incubated with the GST-Pax 8 fusion protein, and proteins able to bind to GST-Pax8 were identified. Several proteins bound to the bait, and the PARP1 protein was characterized as a Pax 8 interactor by multiple independent experiments. PARP1 is the founding member of the human PARP family, whose members (18 different genes) all display a conserved catalytic domain (Ame et al. 2004). PARP1 is a highly conserved nuclear enzyme that binds to single and double-stranded DNA breaks and it is thought to function as a sensor of DNA damage (de Murcia \& Menissier de Murcia 1994, Dantzer et al. 1999).

In this study, we provide evidence of a physical and functional interaction of PARP1 with the transcription factor Pax8. GST-pull down and co-immunoprecipitation assays indicated that PARP1 binds to Pax8 in vitro and in vivo, and in vitro binding studies with purified proteins showed that the interaction between Pax8 and PARP1 is direct. The identification of PARP1 as a partner of Pax 8 is consistent with many reports that suggest the role of PARP1 in the control of gene expression (Oei et al. 1998, D'Amours et al. 1999, Kraus \& Lis 2003). Data reported in the literature propose that PARP1 influences gene transcription modifying directly histones and structural proteins of the chromatin (Poirier et al. 1982, D'Amours 

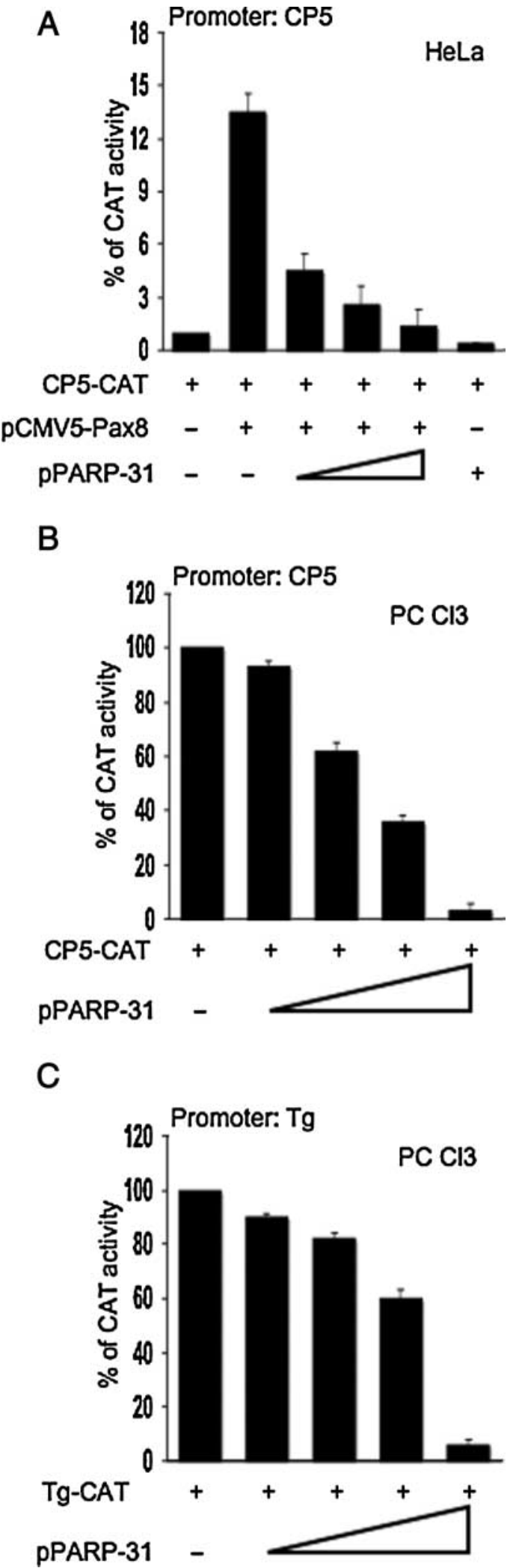

Journal of Molecular Endocrinology (2008) 41, 379-388 et al. 1999, Huang et al. 2006) and/or regulating transcription by directly interacting with other DNA binding factors and co-activators (D'Amours et al. 1999, Hassa \& Hottiger 2002). It has been suggested that PARP1 can behave both as an inhibitor or an activator of the bound transcription factors. In fact, PARP1 binds to and inactivates the DNA binding ability of p53 by covalent poly(ADP-ribosyl)ation (Kumari et al. 1998, MendozaAlvarez \& Alvarez-Gonzalez 2001), and it functions as a suppressor of the RAR/RXR signaling (Miyamoto et al. 1999) and of the RNA polymerase II (Oei et al. 1998). On the other hand PARP1 has been reported to act as a transcriptional co-activator for NF-kB (Hassa \& Hottiger 1999, 2002, Hassa et al. 2001, Nakajima et al. 2004), AP-2 (Kannan et al. 1999) and B-MYB (Cervellera \& Sala 2000). Depending on the different situation, its enzymatic activity has been shown to be necessary as well as unnecessary to regulate gene expression (Poirier et al. 1982, Meisterernst et al. 1997, Oei et al. 1998, Miyamoto et al. 1999, Cervellera \& Sala 2000, Hassa et al. 2003). Our findings indicate that PARP1 acts as a potent inhibitor of Pax8 transcriptional activity by interfering with the formation of the Pax8-DNA complex. In particular, our results suggest that PARP1 elicits its repressor activity on Pax8 independently of its automodification.

DNA repair and transcription are apparently closely related; in fact, association of DNA repair factors with the RNA polymerase II complex has been reported (Bardwell et al. 1994, Roy et al. 1994). Data obtained from mice lacking the PARP1 gene demonstrated its role in DNA repair (Wang et al. 1995, de Murcia et al. 1997) and in vitro assays with the purified enzyme and cellular extracts indicated the effect of poly(ADPribosyl)ation on transcriptional repression (Oei et al. 1998). Furthermore, it has been reported that not only PARP1 activation but also its over-expression correlates with various diseases such as malignant melanomas, hepatocellular carcinoma, colorectal carcinoma, and patho-physiological cardiac hypertrophy (Shimizu et al. 2004, Pillai et al. 2005, Staibano et al. 2005, Nosho et al. 2006). Taken together, all these observations indicate

Figure 5 PARP1 strongly inhibits Pax8 transcriptional activity. (A) HeLa cells were transiently transfected with the reporter plasmid CP5-CAT $(2 \mu \mathrm{g})$ with or without the expression vectors encoding for Pax8 (3 ng) and PARP1 (pPARP-31 (see materials and methods) range of $(0.1 \mu \mathrm{g}),(0.2 \mu \mathrm{g}),(0.3 \mu \mathrm{g}))$. $\mathrm{PC} \mathrm{Cl} 3$ cells were transiently transfected with the reporter constructs CP5-CAT $(0.1 \mu \mathrm{g} ; \mathrm{B}), \mathrm{Tg}$-CAT $(0.2 \mu \mathrm{g} ; \mathrm{C})$, in the absence or in the presence of increasing concentration of expression vectors encoding for PARP1 (pPARP-31 (see materials and methods) range of $(0.1 \mu \mathrm{g}),(0.2 \mu \mathrm{g}),(0.5 \mu \mathrm{g}),(1.0 \mu \mathrm{g}))(\mathrm{B}$ and $\mathrm{C})$. The cells were subsequently harvested and assayed for CAT activity. Folds of activation are considered as ratio between values obtained with and without co-transfection of the expression vectors. CMV-LUC was added as internal reference, and CAT values were normalized to the LUC activity. CAT values are the means \pm s.D. for at least three independent experiments. 
that cell stressor, not necessarily associated with DNA damage, could modify the expression level of PARP1 and, in this way, regulate transcription by both a specific and/or a general mechanism.

In this work, we propose that PARP1 acts a co-factor of Pax8, which is essential to preserving the physiological thyroid context and to allow the fine-tuning of the differentiated thyroid phenotype. Nevertheless, the observed interaction between PARP1 and Pax8 calls for additional studies to define the exact role of PARP1 in the transcriptional regulation of thyroid-expressed genes. It will be of interest to investigate the effect of PARP1 over-expression with respect to proliferation and differentiation of thyroid cells, and to analyze the effect of PARP1 absence, both in vitro by RNAi in differentiated thyroid cells and in vivo by studying the thyroid phenotype of PARP1 knockout mice.

\section{Declaration of interest}

The authors declare that there is no conflict of interest that could be perceived as prejudicing the impartiality of the research reported.

\section{Funding}

This work has been supported by grants from the Associazione Italiana per la Ricerca sul Cancro (AIRC) to $\mathrm{M} \mathrm{Z}$ and from the Ministry of Instruction, University and Research (MIUR FIRB 2001 cod. RBAU01PRLA) to A S T. Di P has been supported by a fellowship from the Federazione Italiana per la Ricerca sul Cancro (FIRC).

\section{Acknowledgements}

The authors gratefully acknowledge $\mathrm{Dr} \mathrm{P}$ Kannan for providing reagents and the Service of Molecular Biology (SBM) of the Stazione Zoologica A Dohrn of Naples for their technical assistance.

\section{References}

Ambesi-Impiombato FS \& Coon HG 1979 Thyroid cells in culture. International Review of Cytology 10 163-172.

Ame JC, Spenlehauer C \& de Murcia G 2004 The PARP superfamily. BioEssays 26 882-893.

Amendola E, De Luca P, Macchia PE, Terracciano D, Rosica A, Chiappetta G, Kimura S, Mansouri A, Affuso A, Arra C et al. 2005 A mouse model demonstrates a multigenic origin of congenital hypothyroidism. Endocrinology 146 5038-5047.

Bardwell AJ, Bardwell L, Iyer N, Svejstrup JQ, Feaver WJ, Kornberg RD \& Friedberg EC 1994 Yeast nucleotide excision repair proteins Rad2 and Rad4 interact with RNA polymerase II basal transcription factor b (TFIIH). Molecular and Cellular Biology 14 3569-3576.

Berlingieri MT, Portella G, Grieco M, Santoro M \& Fusco A 1988 Cooperation between the polyomavirus middle-T-antigen gene and the human c-myc oncogene in a rat thyroid epithelial differentiated cell line: model of in vitro progression. Molecular and Cellular Biology 8 2261-2266.

Caratu G, Allegra D, Bimonte M, Schiattarella GG, D'Ambrosio C, Scaloni A, Napolitano M, Russo T \& Zambrano N 2007
Identification of the ligands of protein interaction domains through a functional approach. Molecular and Cellular Proteomics 6 333-345.

Cervellera MN \& Sala A 2000 Poly(ADP-ribose) polymerase is a B-MYB coactivator. Journal of Biological Chemistry 275 10692-10696.

Chiarugi A 2002 Poly(ADP-ribose) polymerase: killer or conspirator? The 'suicide hypothesis' revisited Trends in Pharmacological Sciences 23 122-129.

Damante G \& Di Lauro R 1994 Thyroid-specific gene expression. Biochimica et Biophysica Acta 1218 255-266.

Damante G, Tell G \& Di Lauro R 2001 A unique combination of transcription factors controls differentiation of thyroid cells. Progress in Nucleic Acid Research and Molecular Biology 66 307-356.

D'Amours D, Desnoyers S, D'Silva I \& Poirier GG 1999 Poly(ADPribosyl)ation reactions in the regulation of nuclear functions. Biochemical Journal 342 249-268.

Dantzer F, Schreiber V, Niedergang C, Trucco C, Flatter E, De La Rubia G, Oliver J, Rolli V, Menissier-de Murcia J \& de Murcia G 1999 Involvement of poly(ADP-ribose) polymerase in base excision repair. Biochimie 81 69-75.

Ding R \& Smulson M 1994 Depletion of nuclear poly(ADP-ribose) polymerase by antisense RNA expression: influences on genomic stability, chromatin organization, and carcinogen cytotoxicity. Cancer Research 54 4627-4634.

Espinoza CR, Schmitt TL \& Loos U 2001 Thyroid transcription factor 1 and Pax8 synergistically activate the promoter of the human thyroglobulin gene. Journal of Molecular Endocrinology 27 59-67.

De Felice M \& Di Lauro R 2004 Thyroid development and its disorders: genetics and molecular mechanisms. Endocrine Reviews 25 722-746.

Fitzsimmons D, Hodsdon W, Wheat W, Maira SM, Wasylyk B \& Hagman J 1996 Pax-5 (BSAP) recruits Ets proto-oncogene family proteins to form functional ternary complexes on a B-cell-specific promoter. Genes and Development 10 2198-2211.

Fusco A, Berlingieri MT, Di Fiore PP, Portella G, Grieco M \& Vecchio G 1987 One- and two-step transformations of rat thyroid epithelial cells by retroviral oncogenes. Molecular and Cellular Biology 7 3365-3370.

Van Gool L, Meyer R, Tobiasch E, Cziepluch C, Jauniaux JC, Mincheva A, Lichter P, Poirier GG, Burkle A \& Kupper JH 1997 Overexpression of human poly(ADP-ribose) polymerase in transfected hamster cells leads to increased poly(ADP-ribosyl)ation and cellular sensitization to gamma irradiation. European Journal of Biochemistry 244 15-20.

Hassa PO \& Hottiger MO 1999 A role of poly (ADP-ribose) polymerase in NF-kappaB transcriptional activation. Biological Chemistry $\mathbf{3 8 0}$ 953-959.

Hassa PO \& Hottiger MO 2002 The functional role of poly(ADPribose) polymerase 1 as novel coactivator of NF-kappaB in inflammatory disorders. Cellular and Molecular Life Sciences $\mathbf{5 9}$ $1534-1553$.

Hassa PO, Covic M, Hasan S, Imhof R \& Hottiger MO 2001 The enzymatic and DNA binding activity of PARP-1 are not required for NF-kappa B coactivator function. Journal of Biological Chemistry 276 $45588-45597$.

Hassa PO, Buerki C, Lombardi C, Imhof R \& Hottiger MO 2003 Transcriptional coactivation of nuclear factor-kappaB-dependent gene expression by $\mathrm{p} 300$ is regulated by poly(ADP)-ribose polymerase-1. Journal of Biological Chemistry 278 45145-45153.

Huang JY, Chen WH, Chang YL, Wang HT, Chuang WT \& Lee SC 2006 Modulation of nucleosome-binding activity of FACT by poly(ADPribosyl)ation. Nucleic Acids Research 34 2398-2407.

Jeggo PA 1998 DNA repair: PARP - another guardian angel? Current Biology 8 R49-R51.

Kannan P, Yu Y, Wankhade S \& Tainsky MA 1999 PolyADP-ribose polymerase is a coactivator for AP-2-mediated transcriptional activation. Nucleic Acids Research 27 866-874.

Kraus WL \& Lis JT 2003 PARP goes transcription. Cell 113 677-683. 
Kumari SR, Mendoza-Alvarez H \& Alvarez-Gonzalez R 1998 Functional interactions of $\mathrm{p} 53$ with poly(ADP-ribose) polymerase (PARP) during apoptosis following DNA damage: covalent poly(ADPribosyl)ation of p53 by exogenous PARP and noncovalent binding of p53 to the M(r) 85000 proteolytic fragment. Cancer Research $\mathbf{5 8}$ 5075-5078.

Maeda Y, Hunter TC, Loudy DE, Dave V, Schreiber V \& Whitsett JA 2006 PARP-2 interacts with TTF-1 and regulates expression of surfactant protein-B. Journal of Biological Chemistry 281 9600-9606.

Mansouri A, Chowdhury K \& Gruss P 1998 Follicular cells of the thyroid gland require Pax8 gene function. Nature Genetics 19 87-90.

Meisterernst M, Stelzer G \& Roeder RG 1997 Poly(ADP-ribose) polymerase enhances activator-dependent transcription in vitro. PNAS 94 2261-2265.

Mendoza-Alvarez H \& Alvarez-Gonzalez R 2001 Regulation of p53 sequence-specific DNA-binding by covalent poly(ADP-ribosyl)ation. Journal of Biological Chemistry 276 36425-36430.

Miccadei S, De Leo R, Zammarchi E, Natali PG \& Civitareale D 2002 The synergistic activity of thyroid transcription factor 1 and Pax 8 relies on the promoter/enhancer interplay. Molecular Endocrinology 16 837-846.

Missero C, Cobellis G, De Felice M \& Di Lauro R 1998 Molecular events involved in differentiation of thyroid follicular cells. Molecular and Cellular Endocrinology 140 37-43.

Miyamoto T, Kakizawa T \& Hashizume K 1999 Inhibition of nuclear receptor signalling by poly(ADP-ribose) polymerase. Molecular and Cellular Biology 19 2644-2649.

Muchardt C \& Yaniv M 1999 ATP-dependent chromatin remodelling: SWI/SNF and Co. are on the job. Journal of Molecular Biology 293 187-198.

de Murcia G \& Menissier de Murcia J 1994 Poly(ADP-ribose) polymerase: a molecular nick-sensor. Trends in Biochemical Sciences 19 172-176.

de Murcia JM, Niedergang C, Trucco C, Ricoul M, Dutrillaux B, Mark M, Oliver FJ, Masson M, Dierich A, LeMeur M et al. 1997 Requirement of poly(ADP-ribose) polymerase in recovery from DNA damage in mice and in cells. PNAS 94 7303-7307.

Nakajima H, Nagaso H, Kakui N, Ishikawa M, Hiranuma T \& Hoshiko S 2004 Critical role of the automodification of poly(ADP-ribose) polymerase-1 in nuclear factor-kappaB-dependent gene expression in primary cultured mouse glial cells. Journal of Biological Chemistry 279 42774-42786.

Nosho K, Yamamoto H, Mikami M, Taniguchi H, Takahashi T, Adachi Y, Imamura A, Imai K \& Shinomura Y 2006 Overexpression of poly(ADP-ribose) polymerase-1 (PARP-1) in the early stage of colorectal carcinogenesis. European Journal of Cancer 42 2374-2381.

Oei SL, Griesenbeck J, Ziegler M \& Schweiger M 1998 A novel function of poly(ADP-ribosyl)ation: silencing of RNA polymerase II-dependent transcription. Biochemistry 37 1465-1469.

Di Palma T, Nitsch R, Mascia A, Nitsch L, Di Lauro R \& Zannini M 2003 The paired domain-containing factor Pax8 and the homeodomaincontaining factor TTF-1 directly interact and synergistically activate transcription. Journal of Biological Chemistry 278 3395-3402.

Pasca di Magliano M, Di Lauro R \& Zannini M 2000 Pax8 has a key role in thyroid cell differentiation. PNAS 97 13144-13149.

Pavri R, Lewis B, Kim TK, Dilworth FJ, Erdjument-Bromage H, Tempst P, de Murcia G, Evans R, Chambon P \& Reinberg D 2005 PARP-1 determines specificity in a retinoid signaling pathway via direct modulation of mediator. Molecular Cell 18 83-96.

Pieper AA, Verma A, Zhang J \& Snyder SH 1999 Poly (ADP-ribose) polymerase, nitric oxide and cell death. Trends in Pharmacological Sciences 20 171-181.

Pillai JB, Russell HM, Raman J, Jeevanandam V \& Gupta MP 2005 Increased expression of poly(ADP-ribose) polymerase-1 contributes to caspase-independent myocyte cell death during heart failure. American Journal of Physiology. Heart and Circulatory Physiology 288 H486-H496.
Plachov D, Chowdhury K, Walther C, Simon D, Guenet JL \& Gruss P 1990 Pax8, a murine paired box gene expressed in the developing excretory system and thyroid gland. Development 110 643-651.

Poirier GG, de Murcia G, Jongstra-Bilen J, Niedergang C \& Mandel P 1982 Poly(ADP-ribosyl)ation of polynucleosomes causes relaxation of chromatin structure. PNAS 79 3423-3427.

Roy R, Adamczewski JP, Seroz T, Vermeulen W, Tassan JP, Schaeffer L, Nigg EA, Hoeijmakers JH \& Egly JM 1994 The MO15 cell cycle kinase is associated with the TFIIH transcription-DNA repair factor. Cell 79 1093-1101.

Shevchenko A, Wilm M, Vorm O \& Mann M 1996 Mass spectrometric sequencing of proteins silver-stained polyacrylamide gels. Analytical Chemistry 68 850-858.

Shimizu S, Nomura F, Tomonaga T, Sunaga M, Noda M, Ebara M \& Saisho H 2004 Expression of poly(ADP-ribose) polymerase in human hepatocellular carcinoma and analysis of biopsy specimens obtained under sonographic guidance. Oncology Reports 12 821-825.

Simbulan-Rosenthal CM, Rosenthal DS, Boulares AH, Hickey RJ, Malkas LH, Coll JM \& Smulson ME 1998 Regulation of the expression or recruitment of components of the DNA synthesome by poly(ADP-ribose) polymerase. Biochemistry 37 9363-9370.

Simbulan-Rosenthal CM, Rosenthal DS, Luo R, Samara R, Espinoza LA, Hassa PO, Hottiger MO \& Smulson ME 2003 PARP-1 binds E2F-1 independently of its DNA binding and catalytic domains, and acts as a novel coactivator of E2F-1-mediated transcription during re-entry of quiescent cells into S phase. Oncogene 22 8460-8471.

Sinclair AJ, Lonigro R, Civitareale D, Ghibelli L \& Di Lauro R 1990 The tissue-specific expression of the thyroglobulin gene requires interaction between thyroid-specific and ubiquitous factors. European Journal of Biochemistry 193 311-318.

Staibano S, Pepe S, Lo Muzio L, Somma P, Mascolo M, Argenziano G, Scalvenzi M, Salvatore G, Fabbrocini G, Molea G et al. 2005 Poly(adenosine diphosphate-ribose) polymerase 1 expression in malignant melanomas from photoexposed areas of the head and neck region. Human Pathology 36 724-731.

Vascotto C, Salzano AM, D'Ambrosio C, Fruscalzo A, Marchesoni D, di Loreto C, Scaloni A, Tell G \& Quadrifoglio F 2007 Oxidized transthyretin in amniotic fluid as an early marker of preeclampsia. Journal of Proteome Research 6 160-170.

Wang ZQ, Auer B, Stingl L, Berghammer H, Haidacher D, Schweiger M \& Wagner EF 1995 Mice lacking ADPRT and poly(ADPribosyl)ation develop normally but are susceptible to skin disease. Genes and Development 9 509-520.

de Wet JR, Wood KV, DeLuca M, Helinski DR \& Subramani S 1987 Firefly luciferase gene: structure and expression in mammalian cells. Molecular and Cellular Biology 7 725-737.

Wheat W, Fitzsimmons D, Lennox H, Krautkramer SR, Gentile LN, McIntosh LP \& Hagman J 1999 The highly conserved betahairpin of the paired DNA-binding domain is required for assembly of Pax-Ets ternary complexes. Molecular and Cellular Biology 19 2231-2241.

Xu L, Glass CK \& Rosenfeld MG 1999 Coactivator and corepressor complexes in nuclear receptor function. Current Opinion in Genetics $\mathcal{E}$ Development 9 140-147.

Zannini M, Francis-Lang H, Plachov D \& Di Lauro R 1992 Pax-8, a paired domain-containing protein, binds to a sequence overlapping the recognition site of a homeodomain and activates transcription from two thyroid-specific promoters. Molecular and Cellular Biology 12 4230-4241.

Zhang W \& Chait BT 2000 ProFound: an expert system for protein identification using mass spectrometric peptide mapping information. Analytical Chemistry 72 2482-2489.

Received in final form 30 July 2008

Accepted 3 September 2008

Made available online as an Accepted Preprint 3 September 2008 